\title{
Analysis of Antibiotics Susceptibility of Old and Fresh ATCC Strain of Staphylococcus aureus by Standard Agar Diffusion Technique
}

\author{
Marufa Zerin Akhter ${ }^{1 *}$, Ibrahim Khalil ${ }^{1}$, Priyanath Roy $^{1}$ and Mir Mohammad Ibna Masud ${ }^{2}$ \\ ${ }^{1}$ Department of Microbiology, University of Dhaka, Dhaka 1000, Bangladesh, ${ }^{2}$ Quality Control Department, Beximco Pharmaceuticals Limited, Tongi \\ 1711, Gazipur, Bangladesh
}

[Received 02 December 2007; Accepted 08 December 2007]

\begin{abstract}
A comparative study of an old and fresh ATCC strain of Staphylococcus aureus was carried out to determine the mechanism of antibiotic resistance of the old one, which had been preserved in lyophilized condition. Five different antibiotics having five different modes of action were used. They included amoxicillin, azithromycin, neomycin, ciprofloxacin and polymixin B. Agar diffusion technique was followed to determine the antibiotic sensitivity. It was observed that the old strain showed the highest resistance against amoxicillin, whereas no remarkable changes in the sensitivity pattern were observed against polymixin B and neomycin. In case of azithromycin and ciprofloxacin, the old strain showed resistance up to some extent. From these results it was clearly evident that in the controlled preserved conditions, cell wall-mediated resistance was predominating, while the cell membrane- and $30 \mathrm{~S}$ ribosome-mediated resistance were the least likely ones. The nucleic acid synthesis inhibitors and the 50S ribosomal protein synthesis inhibitor lied in between these two extremes showing variations up to some extent in the sensitivity pattern between the old and fresh ATCC strain of S. aureus.
\end{abstract}

Keywords: Staphylococcus aureus, Antibiotic resistance mechanism

\section{Introduction}

ATCC cultures have been cited in national and international standards for many years. Cultures are used in performance testing of products, as positive and negative controls, as indicator organisms and as identification standards. ATCC cultures are also used for the determination of potency of antibiotics or other specific properties of certain substances and preparations where these properties cannot be adequately determined by chemical or physical means. For some antibiotic bioassay fresh Staphylococcus aureus is used.

Development of resistance to antimicrobial agents by staphylococci is a major concern primarily because they are still associated with hospital and community acquired infections ${ }^{1}$. The organisms exhibit remarkable versatility in their behaviour towards antibiotics ${ }^{2}$ with some strains having overcome most commonly used drugs. Exposure to new antibiotics often results in further selection of homologues resistant strains ${ }^{3}$, a phenomenon particularly favoured by irrational antibiotic administration. Infection with such resistant strains is likely to be more severe and require longer hospitalization with incumbent increased costs, than infection with susceptible strains ${ }^{4}$.

Staphylococcus aureus, a common opportunistic pathogen, is carried in the nasal passage, develops resistance very frequently. Humans are a natural reservoir for $S$. aureus and asymptomatic colonization is far more common than infection. Colonization of the nasopharynx, perineum, or skin, particularly if the cutaneous barrier has been disrupted or damaged, may occur shortly after birth and may recur anytime thereafter ${ }^{5}$. It has been recognized historically as a virulent and important human pathogen. Its capacity to produce human diseases has not diminished with the introduction of antibiotics ${ }^{6}$. It is still one of the most frequently encountered single bacterial species in hospitals and continues to be a frequent cause of burns and wound sepsis ${ }^{7}$. Staphylococcal resistance was reported shortly after penicillin was introduced and within approximately 6 years, 25\% of hospital strains were resistant. One to two decades later, $25 \%$ of community isolates were penicillin resistant ${ }^{8-9}$. S. aureus is perhaps the pathogen of greatest concern because of its intrinsic virulence, its ability to cause a diverse array of life-threatening infections and its capacity to adapt to different environmental conditions ${ }^{10-11}$.

The mortality of $S$. aureus bacteraemia remains approximately $20-40 \%$ despite the availability of effective antimicrobials ${ }^{12}$. The mortality of patients with $S$. aureus bacteraemia in the preantibiotic era exceeded $80 \%$, and over $70 \%$ developed metastatic infections $^{13}$. The introduction of penicillin in the early $1940 \mathrm{~s}$ dramatically improved the prognosis of patients with staphylococcal infection. However, as early as 1942, penicillin-

*Corresponding author:

Dr. Marufa Zerin Akhter, Assistant Professor, Department of Microbiology, University of Dhaka, Dhaka 1000, Bangladesh

Tel (Office): (02) 9661920-73, Ext 7751; Tel (Home): (02) 8822015; E-mail: mzakhter@hotmail.com 
resistant staphylococci were recognized, first in hospitals and subsequently in the community ${ }^{14}$. By the late 1960 s, more than $80 \%$ of both community- and hospital-acquired staphylococcal isolates were resistant to penicillin. This pattern of resistance, first emerging in hospitals and then spreading to the community, is now a well-established pattern that recurs with each new wave of antimicrobial resistance ${ }^{15}$.

Routine bioassay of different antibiotics in pharmaceutical industries use fresh antibiotic sensitive ATCC strains of Staphylococcus aureus for the required zones of inhibition in agar diffusion technique. After the specified recommended usage period of two years from the date of opening, these strains are no longer used in the bioassays. These used strains are not discarded also; rather these are preserved by lyophilization in case required again in the course of time. The ATCC supplied S. aureus develop resistance by subculturing and in controlled storage conditions even without exposure to antibiotics or any other contaminating strains.

A comparative study of one such old expired ATCC strain with a fresh ATCC strain was carried out in the present research to find out the mechanism or type of antibiotic resistance that took place in the old culture that was preserved in controlled environment. Five different antibiotics having five different modes of action were used to find out the sites of the cells involved to confer resistance.

\section{Materials and Methods}

Test organism

Staphylococcus aureus was collected from the laboratory of Microbiology of a local pharmaceutical industry. Both the old and new strains had a reference number of ATCC 6538. The collected old strain had been used in that laboratory from 1996 to 1998 for regular bioassay studies and then was preserved by lyophilization. This preserved strain was sub cultured every 6 months.

\section{Culture media used}

Mannitol salt agar was used as selective medium for Staphylococcus aureus. Blood agar medium was used for observation of haemolytic pattern of bacterium. Nutrient agar medium was used for subculturing purpose and for studying the morphological properties of the bacterium. For the identification of organism Baird-Parker medium was used, which gives greyblack shiny colonies often surrounded by clear zone with or without opaque haloes around the colonies.

\section{Serological analysis}

Rapid latex agglutination test was carried out to determine the agglutination property of the test organism.

\section{Preparation of inoculum}

The lyophilized ATCC strain of Staphylococcus aureus preparation was allowed to equilibrate to room temperature (22 to $25^{\circ} \mathrm{C}$ ). The hydration fluid and the dilution fluids were warmed to 35 to $37^{\circ} \mathrm{C}$ prior to use. Two pellets were removed and placed into the 2.0-ml vial of hydration fluid. The vial with the hydrated material was recapped and replaced into a 35 to $37^{\circ} \mathrm{C}$ incubator for $30 \mathrm{~min}$ to assure complete hydration. From the resuscitated $S$. aureus stock culture, agar slant cultures were prepared. From that growth on the slant $10^{7}$ to $10^{8}$ cell $/ \mathrm{ml}$ cell suspensions were prepared with $0.9 \% \mathrm{NaCl}$ solution.

\section{Test antibiotics}

The antibiotics used were amoxicillin (inhibits bacterial cell wall synthesis), azithromycin (inhibits protein synthesis, acting on $50 \mathrm{~S}$ subunit), neomycin (inhibits protein synthesis, acting on $30 \mathrm{~S}$ subunit), ciprofloxacin (inhibits nucleic acid synthesis) and polymixin B (inhibits cell membrane synthesis). According to the British Pharmacopoeia (BP) ${ }^{16}$ and the United States Pharmacopoeia (USP) ${ }^{17}$, the Staphylococcus aureus yields a clear measurable zone of inhibition (20-25 mm) and a linear response in the range from 0.5 to $4.0 \mu \mathrm{g} / \mathrm{ml}$ of the standard antibiotic solution. Different concentrations between 0.5 and $40 \mu \mathrm{g} / \mathrm{ml}$ of both standard and sample of amoxicillin, azithromycin, ciprofloxacin, neomycin and polymixin B were prepared. The sample was prepared from commercial finished products of corresponding raw materials.

\section{Preparation of assay plates}

Melted agar $(400 \mathrm{ml})$ was cooled to approximately $48^{\circ} \mathrm{C}$ and inoculated with the appropriate test organism (1-2 ml inoculum for each $100 \mathrm{ml}$ ) and poured into 12 " x 12 " plate immediately after inoculating to prevent undue death of the bacteria at the temperature of the liquefied agar. After the agar had set, 64 wells were cut out from the agar with a steel borer.

\section{Dispensing of antibiotic solution and incubation}

The dispensation technique used was the " $8 \times 8(2+2)$ Latin Square Design”, which gives precision of sensitivity. The different concentrations of antibiotics were dispensed in 64 different wells in a randomized manner to eliminate errors due to drift, to edge and time effects, variation in depth in agar, and in the volume of seeding inoculums. Thus estimates of potency are normally obtained which are unbiased by these various effects, leaving only a small residual error inherent in microbiological assay due to imperfect replication of the zone diameters. One standard and one sample solution at two levels (high and low, with high containing twice the concentration than the low) each are applied in 16 zones for each level in a true Latin Square. The standard and sample solution, each of $140 \mu \mathrm{l}$, were dispensed into the wells with even number ( 2 and 4 for standard and 6 and 8 for sample) for lower concentration and odd numbers ( 1 and 3 for standard and 5 and 7 for sample) for higher concentration with a micropipette and kept undisturbed for half an hour and then incubated at $32-35^{\circ} \mathrm{C}$ for 16 to $18 \mathrm{~h}$. Generally, the more potent the antibiotic and the fresh or non-resistant microorganism is the larger the zone of inhibition. 


\section{Measurement of inhibition zones}

The diameters of the inhibition zones for both the lower and higher dilutions were measured with calibrated digital slide callipers. The average zones of inhibition of specific concentration were calculated from 'standard high' (Std-H) and ‘sample high' (Smp-H) from the following equation:

Average zone of inhibition against a specific concentration of antibiotic $=$ $(S t d-H+S m p-H) \div 2$ and $(S t d-L+S m p-L) \div 2$,

where $S t d-H=$ standard high, $S m p-H=$ sample high, Std- $L=$ standard low, $S t d-L=$ sample low. If two or more results obtained in different plates against specific concentration of antibiotic varied, the average zone of inhibition was calculated.

\section{Results and Discussion}

Cultural, biochemical and serological tests of both the old and new strains of $S$. aureus produced same results, which were indicative of the purity of both the cultures. Both the strains were latex agglutination test positive and showed all the typical cultural characteristics and biochemical properties of Staphylococcus aureus.

The sensitivity pattern of both old and fresh strains of $S$. aureus toward "standard" and "sample" antibiotic showed that the old one became resistant to amoxicillin. At a very high concentration (10 $\mu \mathrm{g} / \mathrm{ml})$, it showed some sensitivity, although the zone diameters were far less than the fresh strain (Figure 1). At this concentration, the average inhibition zones of the old and new strains were $12.75 \mathrm{~mm}$ and $24.45 \mathrm{~mm}$ respectively that was significant different. The higher concentrations showed similar or even more differences in zone diameters between these two strains.

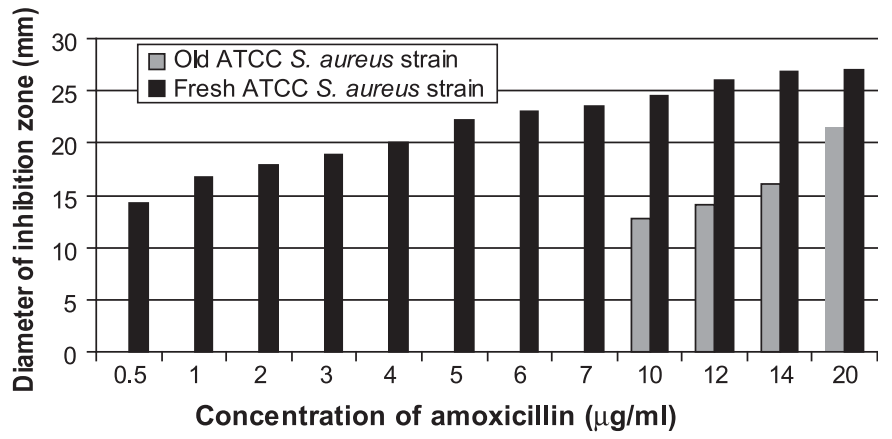

Figure 1. Sensitivity of old and fresh ATCC strains of Staphylococcus to different concentrations of amoxicillin.

The sensitivity pattern of both old and fresh strains of $S$. aureus toward "standard" and "sample” neomycin showed similar sensitivity pattern although the old one showed a slightly smaller zones of inhibition, which was not that significant (Figure 2). At the low concentration of $0.5 \mu \mathrm{g} / \mathrm{ml}$, both the strains did not produce any inhibition zone. The zones started from $1.0 \mathrm{mg} / \mathrm{ml}$ concentration. At this concentration, average inhibition zones of the old and new strains were $13.74 \mathrm{~mm}$ and $14.05 \mathrm{~mm}$ respectively.

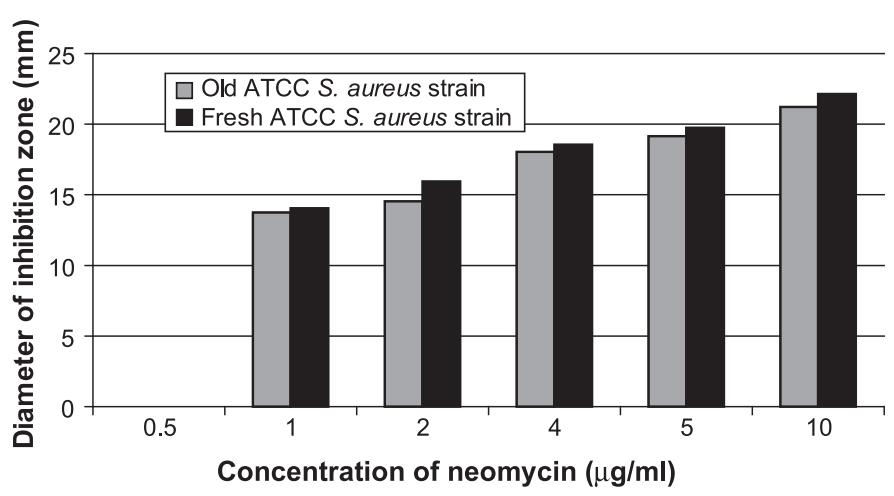

Figure 2. Sensitivity of old and fresh ATCC strains of Staphylococcus to different concentrations of neomycin.

In case of azithromycin, the old and new strains showed similarities in the higher concentrations starting from $2 \mu \mathrm{g} / \mathrm{ml}$ (Figure 3). Although at 0.5 and $1.0 \mu \mathrm{g} / \mathrm{ml}$ concentrations, the sensitivities were quite different. At these concentrations, the old strain was resistant, while the fresh one showed sensitive inhibition zones. At concentrations of 2 and $10 \mu \mathrm{g} / \mathrm{ml}$, there were significant differences in zone diameter; whereas at concentrations of 4, 5 and $10 \mu \mathrm{g} / \mathrm{ml}$, the zones were only slightly smaller in case of the old strain. At $2 \mu \mathrm{g} / \mathrm{ml}$ concentration, average inhibition zones of the old and new strains were $14.77 \mathrm{~mm}$ and $17.59 \mathrm{~mm}$ respectively.

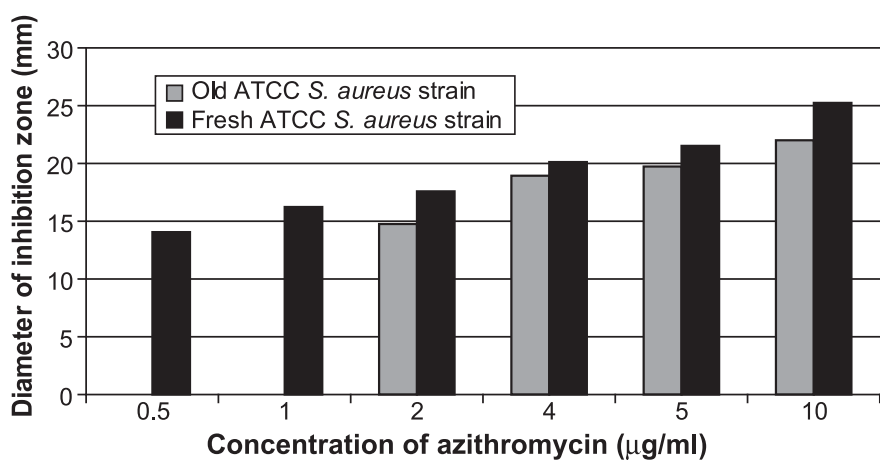

Figure 3. Sensitivity of old and fresh ATCC strains of Staphylococcus to different concentrations of azithromycin.

The sensitivity pattern of ciprofloxacin showed similarities in the higher concentrations starting from $2 \mu \mathrm{g} / \mathrm{ml}$ (Figure 4). At $0.5 \mu \mathrm{g} / \mathrm{ml}$ concentration, both strains did not produce any inhibition zones. At the concentration of $1.0 \mu \mathrm{g} / \mathrm{ml}$, the sensitivities were quite different as at these concentrations the old strain was resistant, while the fresh one showed sensitive inhibition zones. At concentrations of 2, 4, 5 and $10 \mu \mathrm{g} / \mathrm{ml}$, the zone diameters were significantly different. At $2 \mathrm{mg} / \mathrm{ml}$ concentration, average inhibition zones of the old and new strains were $14.05 \mathrm{~mm}$ and $16.34 \mathrm{~mm}$ respectively. 


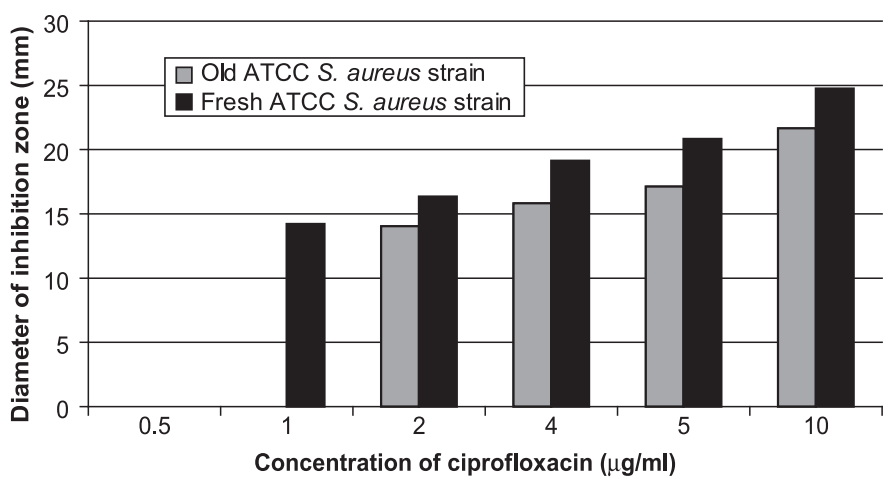

Figure 4. Sensitivity of old and fresh ATCC strains of Staphylococcus to different concentrations of ciprofloxacin.

The sensitivity pattern of both old and fresh strains of S. aureus toward "standard" and "sample" polymyxin B was almost similar at all the concentrations used, although the old one showed slightly smaller zones of inhibition (14.23 mm vs. $14.74 \mathrm{~mm}$ respectively) at $8 \mu \mathrm{g} / \mathrm{ml}$ concentration (Figure 5). At lower concentrations, both the strains were unable to produce any inhibition zone.

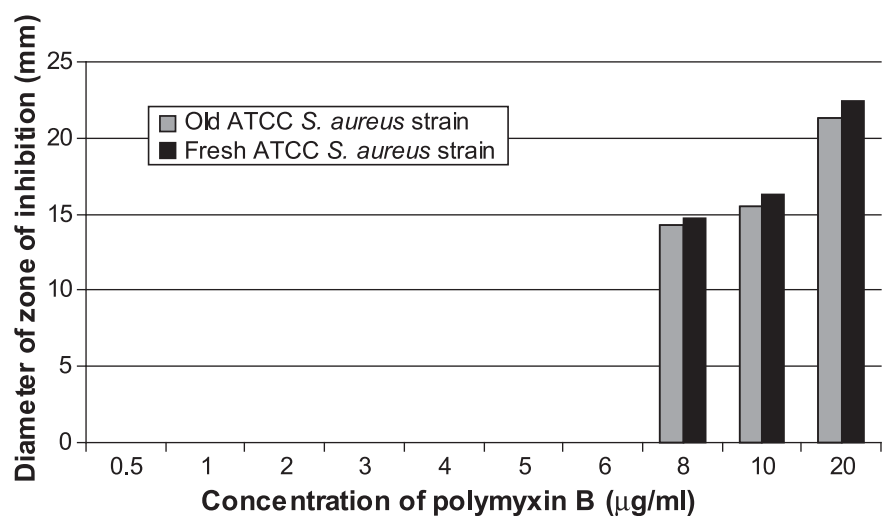

Figure 5. Sensitivity of old and fresh ATCC strains of Staphylococcus to different concentrations of polymyxin B.

The mechanism by which these organisms become drug resistance is not yet fully investigated or understood. The possible pressures these strains go through are 'repeated subculturing' and the 'cryogenic shock' they experience due to repeated freezing and thawing. As the chance of attaining external pieces of DNA conferring resistance (e.g., R plasmids, transposons from other bacteria) is ruled out in the preserved controlled environment, the other option is the consequence of mutations in the chromosomal DNA (chromosome-mediated resistance). Although it has been reported that "penicillinase", which is also a cell wall synthesis inhibitor, is typically plasmid encoded and can be readily transferred by transduction or conjugation. These characteristics account for methicillin-susceptible, penicillinaseproducing strains being genetically diverse and polyclonal.

Staphylococcal resistance to penicillin is mediated by blaZ, the gene that encodes $\beta$-lactamase. This predominantly extracellular enzyme, synthesized when staphylococci are exposed to $\beta$-lactam antibiotics, hydrolyzes the $\beta$-lactam ring, rendering the $\beta$-lactam inactive. The gene blaz is under the control of two adjacent regulatory genes, the antirepressor blaR 1 and the repressor blaI ${ }^{18}$. Unlike plasmid-encoded penicillinase, the methicillin resistance determinant, mec, is chromosomally encoded ${ }^{18-19}$. Horizontal transfer of mec is thought to be relatively rare; only a handful of ancestral strains account for all clinical isolates worldwide ${ }^{20}$. mecA is responsible for synthesis of penicillin-binding protein 2a (PBP2a; also called PBP2') a 78-kDa protein ${ }^{21-22}$. PBPs are membrane-bound enzymes that catalyze the transpeptidation reaction that is necessary for cross-linkage of peptidoglycan chains $^{23}$. Resistance to quinolones results from the stepwise acquisition of chromosomal mutations. The confluence of high bacterial density, the likely pre-existence of resistant subpopulations, and the sometimes limited quinolone concentrations achieved at sites of staphylococcal infections creates an environment that fosters selection of resistant mutants ${ }^{24}$.

One also should not rule out that the physical changes that occur in the cells due to lyophilization to have some kind of effect on the drug sensitivity pattern of the strains. Unfortunately, scientific study reports that specifically emphasized on the effect of lyophilization on drug sensitivity are scarce, whereas quite a number of reports are available on the effect of lyophilization on some other features of $S$. aureus and other bacteria.

A previous study carried out on the comparison with control stock cultures maintained by bimonthly sub-cultivation on brain heart infusion (BHI) agar slants indicated that viability of the organisms was best preserved in $15 \%$ honey. When freezing and freeze-drying were compared, superiority was achieved by the latter. Quantitative activities of acid phosphatase, DNase, and coagulase remained constant in all subcultures. Also, while no loss of virulence for mice was observed with these methods, some did occur with the stock subcultures on BHI agar slants ${ }^{25}$. Another study carried out by Korkeala and Hirvela ${ }^{26}$ on the coagulase production of 77 coagulase-positive $S$. aureus strains stressed (e.g., reduced $\mathrm{pH}$, heat treatment and repeated freezing and lyophilization) before plating on Baird-Parker agar were studied directly from Baird-Parker agar and from BHI broth on strains subcultured first from Baird-Parker agar. They reported that different stress treatments had no effect on coagulase production carried out from BHI broth.

The survival rates of 10 species of microorganisms were investigated after freeze-drying and preserving in a vacuum at $5^{\circ} \mathrm{C}^{27}$. The survival rates varied with species. The survival rates immediately after freeze-drying were different among yeast, Grampositive bacteria, and Gram-negative bacteria, and the change in the 10-year survival rate was species-specific. Survival rates after the drying of Gram-positive bacteria, i.e., Brevibacterium flavum, B. lactofermentum, Corynebacterium acetoacidophilum, C. gultamicum and Streptococcus mutans, were around $80 \%$. 
The survival rate of Brevibacterium and Corynebacterium did not decrease greatly during the storage period, whereas the rate of S. mutans decreased to about $20 \%$ after 10 years. Survival rates after the drying of Gram-negative bacteria, i.e., Escherichia coli, Pseudomonas putida, Serratia marcescens and Alcaligenes faecalis, were around $50 \%$. The survival rate decreased for the first 5 years and then stabilized to around 10\% thereafter.

The survival of a variety of species of microorganism were studied by Miyamoto-Shinohara and co workers ${ }^{28}$ following storage for up to 20 years had been analyzed. The organisms were freezedried, sealed in ampoules under vacuum $(<1 \mathrm{~Pa}$ ) and stored in the dark at $5^{\circ} \mathrm{C}$. The study found excellent survival after freeze-drying of each species that might be attributable to the high level of desiccation and to sealing under vacuum. No study in this area states clearly any drastic affect of lyophilization on bacterial species.

From the present investigation it was observed that the old strain became resistant to amoxicillin. At a very high concentration of $10 \mu \mathrm{g} / \mathrm{ml}$, it showed some sensitivity, although the zone diameters were far less than the fresh strain. At and above this concentration, although inhibition zones were observed for the old strain, the differences in diameters with that of the fresh strain were quite high.

On the other hand, no significant changes in the sensitivity patterns were observed in case of both polymixin B and neomycin. There were only slight differences in zone diameters showing a little variation in sensitivity between the old and fresh ATCC strains. The sensitivity of the nucleic acid synthesis inhibitor "ciprofloxacin" and the 50S ribosomal protein synthesis inhibitor "azithromycin" lied in between these two extremes showing variations in sensitivity between the old and fresh ATCC strains up to some extent. If the extent of resistance is written in a decreasing order of magnitude according to the present study, it would be, amoxicillin > azithromycin > cipofloxacin > neomycin > polymixin B. From these results it was clearly evident that in the controlled preserved conditions, cell wall mediated resistance was predominating in conferring resistance to $S$. aureus cells.

As the cultures were kept lyophilized for a long time and had gone through repeated freezing and thawing, the possibilities of altered cell wall and other cellular structures cannot be overlooked. Although the extent and qualities of the growth of the resuscitated old strain and also biochemical and serological results matched to the fresh one, still further studies are required to be ascertained that no external DNAs were involved in the resistance mechanism.

The present research was only an initial effort to determine the mode of resistance taking place in the old lyophilized stock culture of $S$. aureus. Further studies must be carried out to ascertain whether the resistance observed really came about from genetic mutation or was it from a chance uptake of external DNA during the subculturing process or whether it was due to the cryogenic effect of repeated freeze thaw or lyophilization. Plasmid DNA extraction and typing of these strains by pulsed-field gel electrophoresis (PFGE) can be carried out to determine the presence of resistant plasmids and to determine any significant changes in the DNA respectively in the old strain. A complete investigation in the present study area will contribute at least up to some extent in the understanding and research of drug resistance of $S$. aureus preserved in controlled conditions.

\section{References}

1. Locksley RM, Cohen MI, Quinn TC, Tompkins LS, Coyle MB, Kirihara JM \& Counts. 1982. Multiple antibiotic resistant Staphylococcus aureus: Introduction, transmission and evolution of nosocomial infection. Ann Int Med. 9: 317-324.

2. Grassi GG. 1988. Infections by Gram-positive bacteria: An overview. J Antimicrob Chemother. 21(Suppl. C): 1-7.

3. Haley RN, Hightower AW, Khabbaz RF, Thornsberry C, Martone WJ, Allen JR \& Hughes JM. 1982. The emergence of methicillin-resistant Staphylococcus aureus infections in the United State hospitals: Possible role of the housestaff- patient transfer circuit. Ann Int Med. 97: 297308.

4. Baron EJ. 1992. The detection, significance and rationale for control of methicillin-resistant Staphylococcus aureus. Clin Microbiol News Lett. 14: 129.

5. Payne MC, Wood HF, Karakawa W \& Gluck L. 1966. A prospective study of staphylococcal colonization and infections in newborns and their families. Am J Epidemiol. 82: 305-316.

6. Waldvogel FA. 1990. Staphylococcus aureus (including toxic shock syndrome). In Principles and Practice of Infectious Disease (Mandell GL, Douglas RG Jr \& Benneth JE eds), $3^{\text {rd }}$ edn, pp 1489-1512. Churchill Livingstone, New York.

7. Emmerson M. 1994. Nosocomial staphylococcal outbreak. Scandinavian J Infect Dis. 93: 47-54.

8. Gould JC \& Cruikshank JD. 1957. Staphylococcal infection in general practice. Lancet. 2: 1157-1161.

9. Harris DM \& Wise PJ. 1969. Penicillinase producing staphylococci in general practice and their control by cloxacillin. Practitioner. 203: 207-211.

10. Lowy FD. 1998. Staphylococcus aureus infections. $N$ Engl J Med. 339: $520-532$.

11. Waldvogel FA. 2000. Staphylococcus aureus (including staphylococcal toxic shock). In Principles and Practice of Infectious Diseases (Mandell GL, Bennett JE \& Dolin R eds), pp 2069-2092. Churchill Livingstone, Philadelphia.

12. Mylotte JM, McDermott C \& Spooner JA. 1987. Prospective study of 114 consecutive episodes of Staphylococcus aureus bacteremia. Rev Infect Dis. 9: 891-907.

13. Skinner D \& Keefer CS. 1941. Significance of bacteremia caused by Staphylococcus aureus. Arch Intern Med. 68: 851-875.

14. Rammelkamp CH \& Maxon T. 1942. Resistance of Staphylococcus aureus to the action of penicillin. Proc Royal Soc Exper Biol Med. 51: 386-389.

15. Chambers HF. 2001. The changing epidemiology of Staphylococcus aureus? Emerg Infect Dis. 7: 178-182.

16. BP. 1993. British Pharmacopoeia (BP), Vol 1. Her Majesty’s Stationary Office (HMSO), London.

17. USP. 1995. United States Pharmacopoeia (USP), Vol 23. Mack Publishing Co, Eastern Pennsylvania.

18. Kernodle DS. 2000. Mechanisms of resistance to b-lactam antibiotics. In Gram-Positive Pathogens (Fischetti VA, Novick RP, Ferretti JJ, Portnoy DA \& Rood JI eds), pp 609-620. ASM Press, Washington DC. 
19. Chambers HF. 1997. Methicillin resistance in staphylococci: Molecular and biochemical basis and clinical implications. Clin Microbiol Rev. 10: 781-791.

20. Kreiswirth B, Kornblum J, Arbeit RD, Eisner W, Maslow JN, McGeer A, et al. 1993. Evidence for a clonal origin of methicillin resistance in Staphylococcus aureus. Science. 259: 227-230.

21. Hartman BJ \& Tomasz A. 1984. Low-affinity penicillin-binding protein associated with beta-lactam resistance in Staphylococcus aureus. J Bacteriol. 158: 513-516.

22. Song MD, Wachi M, Doi M, Ishino F \& Matsuhashi M. 1987. Evolution of an inducible penicillin-target protein in methicillin-resistant Staphylococcus aureus by gene fusion. FEBS Lett. 221: 167-171.

23. Ghuysen JM. 1994. Molecular structures of penicillin-binding proteins and beta-lactamases. Trends Microbiol. 2: 372-380.
24. Hooper DC. 2002. Fluoroquinolone resistance among Gram-positive cocci. Lancet Infect Dis. 2: 530-538.

25. Ohtomo T, Yoshida K, Iizuka H \& San Clemente CL. 1978. Relative stability of biological properties in encapsulated strains of Staphylococcus aureus after freezing and freeze-drying. Cryobiology. 15(4): 461-468.

26. Korkeala H \& Hirvela V. 1981. The effect of various stress treatments on the coagulase test in Staphylococcus aureus. Nord Vet Med. 33(9-11): 434-440.

27. Miyamoto-Shinohara Y, Imaizumi T, Sukenobe J, Murakami Y, Kawamura S \& Komatsu Y. 2000. Survival rate of microbes after freeze-drying and long-term storage. Cryobiology. 41(3): 251-255.

28. Miyamoto-Shinohara Y, Sukenobe J, Imaizumi T \& Nakahara T. 2006. Survival curves for microbial species stored by freeze-drying. Cryobiology. 52(1): 27-32. 